\title{
Restauración monumental: ¿el método en crisis?
}

\author{
Monumental restoration: the method in crisis?
}

\author{
A. González-Moreno Navarro(*)
}

\section{RESUMEN}

Este artículo repasa los últimos años de la restauración arquitectónica en España, y su evolución. Se inicia con las experiencias de una época en la que la práctica de la restauración se abordaba como un hecho compositivo y funcional, tratado casi como la arquitectura de nueva planta. La evolución de conceptos Ilega a la introducción de una metodología de trabajo basada en los distintos aspectos y valores que constituyen el patrimonio.

Pero la experiencia viene a demostrar la enorme dificultad en su aplicación, y en la interdisciplinariedad del equipo de trabajo, así como en la sobrevaloración de los medios, más que en los fines.

\section{SUMMARY}

This article reviews the last years of architectural restoration in Spain and its evolution. Starts with the experiences of a time in which the practice of restoration was addressed as a compositional and functional work, treated almost as the architecture of the new plant. The evolution of concepts comes to the introduction of a work methodology based on different aspects and values that constitute the heritage.

But the experience goes to show the enormous difficulty in its application, the interdisciplinarity of the team, and the overvaluation of the media, more than the finality.
Palabras clave: Restauración objetiva; método; patrimonio edificado; valor documental; estudios previos; diagnóstico.
Keywords: Objetive restoration; method; built heritage; documentary value; previous studies; diagnosis. 


\section{INTRODUCCIÓN}

Hace una treintena de años restaurar monumentos en la periferia peninsular española era una aventura arriesgada. Por lo menos para los entusiastas arquitectos defensores del marginado patrimonio monumental que nos incorporábamos entonces a esas tareas más comprometidas. Un único impreso con algunas frases mecanografiadas, remitido desde Madrid, nos unía al monumento con el que nos había tocado bailar. Ninguna información (ni sobre la propiedad ni la historia ni la geometría ni la problemática -ni pasada ni presente ni futura- ni del bien ni de su entorno o contexto) se nos había facilitado junto a aquel solitario papel. Y ningún otro $u$ otra profesional de cualquier rama del conocimiento había recibido el encargo de escudriñar sobre esos aspectos. $\mathrm{Ni}$ nadie del lugar (ni el cura ni el alcalde ni el boticario ni la guardia civil ni siquiera la propiedad) había recibido aviso de que se pensaba actuar en aquel monumento. El monumento, el arquitecto y un papel (en el que se decía "desde ya proyecte usted", que el asunto es urgente), solos, a su suerte. Así empezaba todo.

Y así inicié yo mi actuación profesional en la torre medieval de defensa conocida como La Manresana, en el municipio de Els Prats de Rei, en la comarca de Anoia de la provincia de Barcelona. Era bella y estaba dañada. Y era alta, y su coronación no pudimos verla hasta que llegó una escalera del albañil a quien se adjudicó un primer proyecto hecho con entusiasmo, pero desde la ignorancia. Ni que decir tiene que la obra no se ciñó en absoluto a ese proyecto. Conocer el monumento y sus problemas, algo de su pasado y un poco de su entorno - cosa que fuimos consiguiendo los arquitectos poco a poco y a nuestras expensasnos indujo en el curso de las obras a una revisión total de lo antes proyectado. Creo que acertamos. Al menos en el pequeño mundo de la restauración monumental, una vez acabada, la obra seria bien vista. A quienes no gustó fue a los entusiastas diletantes que conservaban con esmero el museo local y que habían observado, desde lejos, nuestra actuación. Pero de eso me enteré muchos años después, cuando me confesaron lo que les costó empezar a aceptarla. Tampoco supimos entonces si lo que hacíamos gustaba o no a quienes, desde Madrid, habían mandado algunos meses atrás aquel papel huérfano; ni a sus delegados provinciales, ni a los ediles locales. Ni unos ni otros aparecieron jamás por el lugar. Todo el proceso transcurrió por lo tanto en un silencio social sobrecogedor. Las primeras voces no se oyeron hasta que desde Barcelona (para entonces ya se ha- bría consumado la transferencia de competencias) se nos encargó la actuación en el entorno de la torre.

No es que con el traspaso de competencias a la periferia hubieran mejorado los protocolos o los controles. Todo eso siguió igual. La soledad del arquitecto no varió por el hecho de que los nuevos papeles se redactaran por otras gentes o en otro idioma. Lo que ocurrió fue fruto de la casualidad. O, bien mirado, de la suerte (aunque en un principio no viviéramos como tal aquella alteración de nuestro silencioso estatus) (1).

Con nuestro proyecto de entorno aprobado (aunque dudo que nadie antes lo hubiera revisado) empezamos la segunda obra. Una zanja por aquí, un desmonte por allá y un quíteme de ahí esas piedras. A los pocos días apareció por el lugar un personaje para mí desconocido. Nos preguntó qué hacíamos y pasó en seguida del interrogatorio a los lamentos mezclados con suaves improperios. Era un arqueólogo. Para mi sorpresa no llevaba salakov, que era, según nos habían explicado en la Escuela de Arquitectura, con lo que se cubrían, en el tajo, aquellos peculiares profesionales, cuya presencia en nuestras obras debíamos evitar a toda costa. Bien, el caso es que como nunca me fié de la mayor parte de mis antiguos profesores arquitectos, decidí escucharle. Me habló de estratos, de entregas entre estructuras, de cerámicas y otros restos materiales, y de la posibilidad de desvelar la historia desconocida del monumento analizando todo aquello. Pero había que proceder con tiento, dijo; había que actuar con calma y tino, no destruir estructuras (menos aún las entregas entre ellas) y dibujar y documentar todo lo que se encontrara. Era un discurso razonable y le prometimos hacer lo que pudiéramos, que a la postre no sería mucho. El caso fue que aquella educada bronca cambiaría nuestra vida.

Unos años después, cuando yo ya era jefe del Servicio de Monumentos de la Diputación de Barcelona (al cual, mira por donde, se incorporaría más tarde aquel personaje sin salakov), viví otra bronca parecida. Bien, con otras peculiaridades, ya que en ésta los improperios no fueron leves, sino decididamente injuriosos; y públicos, pues se difundieron en la prensa local. Ocurrió en Manlleu, en la comarca de Osona. Unos jóvenes arquitectos colaboradores del Servicio actuaban en una iglesia de origen medieval transformada. Sin encomendarse ni a Dios ni al diablo decidieron un día rebajar los terrenos contiguos. Aparecieron esqueletos, perdón, restos óseos, y una arqueóloga local presentó el suceso ante la opinión pública como un terrible anticipo apoca- 
líptico, acusando a los profesionales de la Arquitectura de incultos y prepotentes.

\section{LA ÍNCLITA RESTAURACIÓN "A LA ESPAÑOLA"}

Cuando todo esto pasaba, la disciplina de la restauración monumental vivía en España uno de los períodos más complejos de su historia, iniciado tras el proceso de recuperación de la normalidad democrática. Algunas circunstancias políticas, culturales y profesionales de la década de los ochenta que vivíamos, habían propiciado que nuestros monumentos pasasen del olvido a un protagonismo no siempre sensato. La crisis económica había revalorizado el patrimonio edificado y éste estaba siendo utilizado tanto para enjugar la falta de equipamientos heredada de la dictadura como para satisfacer las necesidades edificatorias de la joven democracia. Toda esa fiebre restauradora se produjo sin tiempo suficiente ni voluntad manifiesta para plantear un profundo debate profesional sobre cómo y en qué condiciones debían plantearse esas reutilizaciones del patrimonio hasta entonces marginado (2).

La nueva situación de la disciplina había tenido ya algunas consecuencias positivas; por ejemplo, la recuperación de una "actitud creativa" (es decir, específicamente arquitectónica) en la redacción del proyecto de restauración monumental, lo que, desde el siglo XVI, había constituido un "invariante castizo" de la intervención en el patrimonio español, del todo olvidado en la interminable posguerra a causa del predominio entonces de los rescoldos de las antiguas tendencias restauradoras europeas, reinterpretadas en nuestro suelo con una vacua retórica. Aquella recuperación sería reconocida años más tarde como un signo de identidad de la restauración "a la española" (3).

Lo cierto es, sin embargo, que faltados, en general, los arquitectos titulados después de la guerra de una clara conciencia del valor documental del monumento; encerrados los profesionales de la historia en sus palacios de invierno universitarios; obsoleta la legislación e inmóvil la Administración, y a falta por tanto de ese debate al que me refería antes (ni siquiera se había debatido qué tipo de profesionales debían debatir), esa renovada actitud de los arquitectos se convirtió en peligrosa y estaba salpicando nuestra geografía monumental de preocupantes disparates. Fueron por lo tanto comprensibles, aunque algo tardías y excesivamente destempladas y corporativistas, las reacciones de profesionales de las ramas del conocimiento vinculadas a la restau- ración monumental, especialmente de la historia, y de la arqueología en particular, a las que se sumaron, a través de entidades o de la prensa hasta entonces adormecida, algunos o algunas profesionales que se sintieron olvidados o discriminados en aquella fiebre restauradora.

\section{LOS CONFLICTOS COMO APRENDIZAJE}

Dicen los psiquiatras que los conflictos no deben desesperarnos, sino que debemos aprender de ellos. La escena histriónica de aquella arqueóloga de Manlleu, fresco aún el recuerdo de lo vivido junto a la vieja Manresana, y contemplado el panorama de lo que iba ocurriendo en todo el país, me pusieron definitivamente en aviso de que los arquitectos, o bien algo hacíamos mal, o bien debíamos hacerlo diferente si queríamos acabar bien. Fue entonces cuando pude valorar en su profunda dimensión la gravedad de la deficiente educación que en estas materias habíamos recibido en la Escuela de Arquitectura, sobre todo por parte de docentes que (ellos sí, prepotentes) presumían de ser restauradores de monumentos.

Y fue así cuando decidí que, ya que tenia el privilegio de dirigir el primer servicio de monumentos creado por la Administración pública española, debía invertir una parte importante de mi dedicación profesional a reflexionar sobre esos conflictos, a analizar sus causas profundas y obtener conclusiones positivas que redundasen en un mejor planteamiento de nuestra actividad. Debíamos dar por finalizada la época en que la Administración ponía los monumentos en las exclusivas manos de los arquitectos (era claro que la denunciada prepotencia de éstos no era del todo congénita sino fruto de ese inveterado proceder) y plantearnos otra manera de actuar en la que los arquitectos y los demás profesionales que fuera necesario incorporar al proceso pudieran ejercer cada cual su específica función con eficacia, sin tensiones ni mutuas descalificaciones.

En un principio caí en la tentación de creer que lo que en realidad nos separaba a unos y a otros profesionales era una cuestión de criterios, y que debíamos de profundizar en esa dirección si queríamos entendernos. (Al fin y al cabo ese fue el sueño que presidió parte de los debates entre los jóvenes arquitectos adictos al patrimonio cuando, aún no finiquitada la dictadura, nos reuníamos en los archivos históricos de nuestros colegios profesionales). Pero fue un espejismo pasajero. La lectura de la historia de la disciplina de la restauración ya había demostrado el error en que había caído a lo largo 
de dos siglos: la terca búsqueda de alguna teoría que avalase unos "criterios" con validez permanente y universal indiscutible. Por otra parte, la sensibilización de amplias capas de la población y de nuevas regiones del planeta frente a la necesidad de conservar ese patrimonio, habían provocado en ese último cuarto de siglo la irremediable obsolescencia de las teorías que hasta entonces habían pretendido pautar todas las intervenciones (4).

Por otra parte era inútil un acercamiento interprofesional sin un previo conocimiento, el que la Universidad nos había hurtado. En este sentido, pensamos que un primer paso elemental seria intercambiar datos y opiniones sobre los diversos objetivos y los medios intrínsecos de cada profesión, ya que éstos acaban por forjar una determinada mentalidad; una diversa visión de los problemas, casi una visión del mundo, que no es necesario compartir, pero si comprender y respetar (5)

En cualquier caso deberíamos plantearnos unos protocolos que definieran y estableciesen el papel y la función de cada profesión en el complejo quehacer restaurador. Antes, naturalmente, era imprescindible reflexionar sobre la esencia de la restauración monumental (sus objetivos, por ejemplo, siempre difusos y ambiguos hasta entonces, probablemente distintos en función de la mentalidad desde la que se planteasen); sobre la esencia y el alcance del propio concepto de patrimonio monumental, en constante evolución en las últimas décadas, y, por lo tanto, sobre la esencia del monumento, de la cual cada mentalidad profesional tendía a hacer una reducción interesada (6).

Únicamente así podríamos garantizar que el imprescindible cambio que buscábamos no fuera solamente un tratar de repartirse mejor el pastel entre viejos y nuevos prepotentes.

Lo que andábamos buscando, en definitiva, era una metodología que, basada en unos principios conceptuales básicos nos permitieran pautar nuestra actividad como Servicio especializado. El 1985 publicaríamos el primer fruto de nuestro trabajo, el librito Investigación y Diseño. El monumento como documento y objeto arquitectónico. Y unos años después, en la revista Informes de la Construcción (núm. 397, septiembre/octubre de 1988) aparecería un amplio artículo "Restaurar Monumentos, una metodología específica". En este artículo afirmábamos "frente a los que minusvaloran la condición arquitectónica del monumento", la especificidad de éste en el conjunto del patrimonio cultural. "Su condición de objeto arquitectónico vivo, -se dice- con una función social concreta (por su significación colectiva y por su posible uso), la cual le confiere una especificidad que exige que sea tratado con una metodología propia y diferenciada del resto del patrimonio". Y "frente a los que creen que el monumento es sólo arquitectura", se recordaba que en la actuación en los monumentos no había que olvidar nunca el rigor científico del tratamiento del monumento como documento histórico, en el doble aspecto informativo y testimonial. "Estas dos afirmaciones, rotundas y claras" -concluíamos-, han sido los cimientos donde hemos apoyado una metodología propia, que no quiere decir obviamente exclusiva, cuyo rasgo característico es la colaboración interprofesional, planteada desde el respeto y la autonomía de las diversas disciplinas, y que se estructura en cinco etapas: la lectura previa (el análisis del monumento, de sus circunstancias y de la problemática que se ha de resolver); el planteamiento de los objetivos a alcanzar; el proyecto arquitectónico; la ejecución de la obra, y la difusión de la actuación".

\section{LA RESTAURACIÓN OBJETIVA}

Desde la mitad de la década de los años ochenta empezamos a aplicar esta metodología de manera sistemática y rigurosa en todas las actuaciones del Servicio de la Diputación de Barcelona. Y así, enriqueciendo la reflexión con la experiencia, seguimos puliendo, completando y mejorando los documentos y protocolos en los que se recogían los principios básicos y las pautas de actuación. Conté para ese cometido con la ayuda, entre otras personas que aportaron directa o indirectamente sus reflexiones y experiencias, de la historiadora del Arte Raquel Lacuesta, el arqueólogo Alberto López Mullor (definitivamente incorporado al Servicio sin salakov) y el catedrático de construcción y arquitecto José Luís González, de quien soy hermano. Y así, en 1996 pudimos publicar nuestro Método SCCM de Restauración Monumental, o de "restauración objetiva", locución en la que no entendemos el adjetivo como derivado de los conceptos de "certeza" o "irrebatibilidad", sino de acuerdo con su primera acepción académica ("objetivo: perteneciente o relativo al objeto en sí y no a nuestro modo de pensar o de sentir"). "La restauración objetiva -se dice en la introducción- debe ser entendida, por tanto, como aquella en la que -a diferencia de lo que ha sido más habitual hasta ahoracuenta más el objeto (el monumento) -las necesidades objetivas (ahora sí en el sentido de "ciertas") del monumento y de su entorno humano- que la manera de pensar o de sentir del sujeto restaurador, es decir, que las teorías, doctrinas o escuelas genéricas con las que éste pueda identificarse." 
Los principios básicos en que se fundamenta este método SCCM (acrónimo de la denominación original del servicio de monumentos de la Diputación de Barcelona) se resumían así: En cuanto al objeto (el monumento), la comprensión y valoración equitativa de sus tres dimensiones esenciales: la documental, la arquitectónica y la significativa (aspecto este último añadido después de la publicación del artículo de Informes), y la definición de su autenticidad no en función exclusivamente de la originalidad de la materia, sino de la capacidad de ésta de garantizar la permanencia de esos valores esenciales. En cuanto a la acción (la restauración), su concepción como disciplina simultáneamente científica, técnica y creativa, cuyo objetivo genérico es garantizar que la colectividad disfrute de los beneficios derivados de la conservación del patrimonio monumental (7). Para ello, cada acto restaurador debe proteger el triple carácter del monumento en el que se produce partiendo del conocimiento profundo y el análisis crítico de su compleja esencia y de la de su entorno tanto el físico como el social, de la objetivación de los fines de la actuación y de la elección de los medios (las técnicas analíticas, las terapéuticas, y los criterios, conceptuales y proyectivos) no en función de apriorismos ideológicos, sino de esos fines particulares ya establecidos y de su idoneidad y eficacia reales para alcanzar aquella protección. Y en cuanto a los agentes, el indispensable carácter profesional e interdisciplinario de los estudios y trabajos, el papel fundamental de la administración pública (entendida como el conjunto de mecanismos creados por la colectividad para el buen gobierno de sus intereses comunes) y el papel activo de las colectividades destinatarias de las actuaciones.

Por fortuna, nuestra tenaz defensa de la aplicación de este procedimiento como condición indispensable para garantizar que la Diputación de Barcelona pudiera responder en nuestra época a las exigencias de la sociedad respecto de su patrimonio con la misma eficacia con la que la corporación afrontó el mismo reto a principios del siglo XX, convenció a nuestros superiores, políticos y gestores, y durante casi un cuarto de siglo los principios y pautas de la "restauración objetiva" presidieron todo nuestro trabajo.

\section{UN CUARTO DE SIGLO DE UNA NUEVA MENTALIDAD}

Paralelamente a ese proceso, en el conjunto de España fue abriéndose camino durante aquellos años esa nueva mentalidad subyacente a un método de ese tipo. A partir de los primeros años noventa, al menos sobre el papel -otra cosa es lo que ocurriría en la práctica- esa mentalidad se había casi generalizado. Se avivó algo el debate conceptual, se produjo el reencuentro con la cultura de la restauración de la primera mitad del siglo XX, se extendió la conciencia de la necesidad del diálogo y el trabajo interdisciplinario, y se equilibraron hasta cierto punto los aspectos técnicos, científicos y creativos de la restauración, tratando de mejorar la adecuación y eficacia de los proyectos constructivos. Todo ello con una benéfica incidencia, en general, en los planteamientos y la práctica de la restauración monumental española (matizando -pero por fortuna sin que se echara a perder-su idiosincrasia).

En la práctica, como decía, no todos estos nuevos aspectos o acciones se asumieron o desarrollaron con la rectitud y eficacia deseables. El debate conceptual interdisciplinario se limitó a unas pocas ocasiones derivadas de problemas concretos, y más planteado como confrontación, incluso como denuncia, que como diálogo enriquecedor de posturas. Tampoco favoreció ese necesario debate la irrupción en la palestra de agentes extrínsecos, como esos políticos, periodistas y tertulianos, transeúntes en estas materias, que se arrogan la portavocía de la opinión pública, la cual, dicho sea de paso, se ha manifestado siempre con cierta pasividad ante este tipo de problemas y discusiones. Fue un caso paradigmático el de la reconstrucción del teatro romano de la ciudad de Sagunto (Valencia). La polémica saltó a la palestra avivada por una prensa al servicio exclusivo de los intereses partidistas, lo que desvirtuó el fondo de la cuestión, que no era otro que la necesidad de una metodología rigurosa cuando se acomete la restauración con una actitud creativa. Fue una ocasión perdida, ya que, en paralelo a la burda polémica mediática, los profesionales de la arquitectura y los del conocimiento histórico, en vez de afrontar ese tema de fondo, se enzarzaron en una estéril discusión de raíz corporativista.

En cuanto a ese nuevo equilibrio entre las disciplinas que intervienen en la restauración, y la consecuente participación de profesionales de diferentes ramas, es de destacar el incremento durante esos años de los llamados estudios previos, tanto los de carácter histórico como los relacionados con la materialidad del monumento, al convertirse en norma casi universal que los proyectos de restauración debieran ser precedidos de esos tipos de estudios y convertirse este aspecto de la nueva metodología casi en su distintivo más emblemático. 
Sin embargo, las malas prácticas habituales en la Administración pública menguaron los beneficios esperados. Fue habitual, por ejemplo, que la Ilamada "memoria histórica" se sumara al proyecto arquitectónico una vez redactado éste, con lo que de poco sirve para generar cautelas sobre lo que conviene respetar o provocar enriquecedoras imágenes proyectivas. Como también ha sido habitual adjudicar los trabajos de excavación arqueológica junto con los de la obra de restauración, con lo que, indefectiblemente, las conclusiones de los primeros obligan a reformar el proyecto contratado o, simplemente, no se tienen en cuenta. Similares avatares han sufrido muchos otros estudios científicos mal Ilamados "previos", por lo que a menudo la interdisciplinariedad que se propugnaba como indispensable para garantizar la bondad y eficacia de los proyectos de restauración ha devenido simple pluridisciplinaridad, es decir la suma, sin posibilidad alguna de favorecer la sinergia, de estudios, análisis y trabajos variopintos. (Aunque lo más grave fue y sigue siendo que a menudo esa suma de actuaciones profesionales no esté justificada en función de ese objetivo esencial, sino que responda a intereses laborales o de prestigio -profesional o político-, con lo que se subvierte su condición de medio instrumental).

\section{MÉTODO Y VICIOS DE GESTIÓN}

Pero no solamente estas prácticas de la $\mathrm{Ad}$ ministración han trabado el desarrollo o la eficacia de la metodología basada en esa nueva mentalidad germinada en el último cuarto del siglo XX. Otros rancios vicios de gestión política y administrativa han puesto palos en las ruedas. Bien entrado el siglo $X X I$, y tras décadas en que se han sucedido las prédicas de los expertos urgiendo un cambio de actitud, la Administración pública española (central o autonómica, en eso no hay diferencias) continua tratando el proyecto y la ejecución de los trabajos de la restauración monumental con el mismo rasero con que contempla cualquier obra pública. A los efectos legales es prácticamente lo mismo proyectar y ejecutar la restauración de una catedral, un puente o una ermita medievales que construir una autopista o un parvulario de nueva planta. Los mismos sistemas para la selección de profesionales; las mismas normativas técnicas de aplicación en cuanto al proyecto (tanto en el aspecto constructivo como en los de seguridad y accesibilidad); el mismo criterio para la selección de empresa constructora; el mismo sistema de adjudicación de las obras.

Por otra parte, la Administración pública española, en general, no ha avanzado ni en la racionalización de las actuaciones y la distribución de los recursos, ni en la estructuración o mejora de sus propios organismos especializados. La legislación específica (tanto estatal como regional) que hubiera podido constituir uno de los mecanismos para esa racionalización que permitiera implementar la nueva metodología con garantías de eficacia- sigue siendo inadecuada en cuanto a los aspectos relacionados con la intervención en los elementos monumentales. Se persiste en el viejo error de tratar de regular los "criterios" y se olvida establecer y exigir los procedimientos; laguna grave, como pudo comprobarse en la sentencia judicial sobre la ya citada obra del teatro romano de Sagunto. (Nunca una norma legal había llegado con tanta rapidez a la manifiesta obsolescencia como la ley española de Patrimonio de 1985, la que, lamentablemente, sirvió de modelo para todas sus hijas autonómicas).

En este mismo sentido, otro caso de especial gravedad ha sido lo ocurrido en relación a la antigua Alcazaba de la ciudad de Badajoz. A raíz de la denuncia de una pintoresca entidad local, la Sala de lo Contencioso Administrativo del Tribunal de Justicia de Extremadura sentenció el 2003 la obligatoriedad de devolver "a la situación existente con anterioridad a las obras autorizadas con la licencia impugnada" los edificios reutilizados como Facultad de Biblioteconomía y Documentación y Biblioteca General de la Universidad de Extremadura. En el curso de esta obra, por necesidades de proyecto, se habían desmontado algunas fábricas de relativo valor (muros de mampostería, elementos de carpintería deteriorados, una desvencijada cubierta de teja y alguna escalera de bóveda de ladrillo). De la literalidad de la sentencia, ratificada por el Tribunal Supremo, se deduce la obligación de reconstruir todos esos elementos (siempre, es de suponer, con las irregularidades, patologías, defectos y reparaciones sufridas hasta el momento del derribo, que eso quiere decir "situación existente con anterioridad"); incluso, por lo tanto, el deber de volver a construir una cubierta incapaz de garantizar la estanquidad y el aislamiento obligados por otras normas legales vigentes. ${ }_{i} \mathrm{O}$ se refería subliminalmente la sentencia a recuperar sólo la "simple apariencia" del edificio anterior?). Una vez más se ha puesto de manifiesto el abismo que separa las leyes (y, en consecuencia, la actuación de quienes deben juzgar en base a ellas) de la realidad del patrimonio monumental y de la esencia de su restauración, lo que puede hacer baldíos los intentos de mejorar su práctica a través de la adecuación de la metodología específica. 


\section{MÉTODO Y CRISIS}

El presunto arraigo de la mentalidad que subyace en la nueva metodología de la restauración monumental predicada durante este último cuarto de siglo en nuestra sociedad (el arraigo entre los particulares y los profesionales que intervienen en estos procesos, y, muy especialmente, en la Administración pública), ha podido comprobarse en los momentos de crisis, tanto las de raíz económica como las demás. Los síntomas inducen a pensar que los indicios de comprensión y razonable aprehensión de la nueva mentalidad por parte de esos agentes, indicios que nos procuraron hace unos años una desconfiada esperanza, se antojan simples espejismos cuando nos sacude una crisis. La actuación de la Administración pública en el rico patrimonio monumental de la ciudad de Lorca (Murcia) después del terrible terremoto del 11 de mayo de 2011, puede servirnos como pista. Justificados los trabajos inmediatos para evitar nuevas víctimas (cualquier vida humana vale más que el más significado monumento), justificación que, sin embargo, sólo vale durante un corto espacio de tiempo, los trabajos que se acometieron inmediatamente después se hicieron dando la espalda a esa mentalidad metodológica que tantos años de esfuerzo nos costó entre todos fundamentar e intentar arraigar. Con unas prisas no siempre justificadas, se adjudicaron proyectos y obras sin atender a la calificación especializada de quienes recibían los encargos y se demolieron con procedimientos no avalados ni por la prudencia ni por la eficacia algunos de los monumentos dañados, o partes de ellos, con lo que a la acción devastadora del seísmo se sumó la impericia y la ignorancia de algunos profesionales y la prepotencia de una parte de algunos gestores públicos.

Los efectos de la crisis económica que sufrimos en estos momentos han sido igualmente terribles. Es cierto que siempre he defendido que no hay mejor medicina para conservar nuestro patrimonio que una crisis económica. No por la crisis en sí misma, sino porque desgraciadamente no hay peor enemigo del patrimonio que el exceso de dinero público en manos, al alimón, de políticos manirrotos y técnicos iluminados. Pero lo que es bueno, o menos malo, para la conservación (es decir, la subsistencia) del patrimonio ha sido pernicioso para la nueva mentalidad metodológica. Como en el caso del temblor antes comentado, les ha faltado tiempo a los gestores públicos para agarrarse a la crisis como excusa para torpedear los nuevos métodos (de los que les preocupa la presunta dilatación de los costes y de los plazos de ejecución de las obras).
Mi cese en la dirección del Servicio de la Diputación de Barcelona por una cuestión bio-aritmética, coincidió con la explosión de la crisis económica mundial Ilamada del 2008, a la que, curiosamente, los gestores de entonces de la institución provincial habían respondido, entre otras medidas, creando más cargos intermedios, entre ellos los Ilamados gerentes (es decir, una de las respuestas más insensatas). Pues bien, el flamante gerente a quien se confió la gestión (es decir, el control) de las actividades del Servicio de monumentos más antiguo de España, se le ocurrió un original camino para sortear la crisis. Y así, sin más, le pregunto al nuevo responsable técnico del Servicio: "A partir de ahora, ¿no podría usted restaurar un poco peor?" Es decir, vino a decir sin decirlo: "Con la excusa de la crisis, ¿no podemos cargarnos el dichoso Método?".

\section{EL JAMÓN Y LA MORTADELA}

Cuando conocí tan sorprendente iniciativa me acordé inmediatamente de una anécdota familiar (más que una anécdota, quizá una metodología familiar) que he procurado transponer a mi vida en general, tanto la privada como la profesional, y que he predicado siempre que he podido. Una práctica hogareña digna de ser convertida en teoría o principio básico de acción, y digna de ser presentada como tal en una revista técnica y científica como la que acoge este escrito.

Cuando yo era pequeño o jovencito, mi madre compraba a menudo en una mantequería de prestigio que estaba cerca de casa. Los precios de cuanto allí se vendía estaban a la altura del prestigio del local. Si nuestra dieta familiar se hubiera basado en esos productos, posiblemente a mitad de cada mes nos hubiéramos visto obligados a pasar a una dieta más radical... Mi madre entraba a menudo, pero compraba poco cada vez. Normalmente, jamón. El mejor jamón que se podía comprar en el barrio y posiblemente en la ciudad. Aquel día era fiesta. Otros días, quizá en las postreras semanas del mes o en épocas de más gastos escolares o de solaz colectivo, también entraba mi madre en la mantequería, pero compraba mortadela. La teoría que sustentaba su conducta era impecable. Cuando no se alcanza para comprar el mejor jamón, nunca se debe comprar peor jamón. Es preferible la mortadela; la mejor mortadela, por supuesto. En épocas de crisis se puede restaurar menos; incluso sólo hacer obras de estricto mantenimiento. Nunca restaurar peor. Nunca restaurar, ni mantener, sin método. Pero antes, claro está, hay que conocer el método, su razón de existir y las ventajas de su aplicación. 


\section{LA CRISIS INTRÍNSECA DEL MÉTODO}

No sería eficaz, sin embargo, achacar la innegable crisis actual de la metodología propugnada en las décadas finales del siglo pasado a razones puramente extrínsecas, desde los inveterados vicios de la Administración a las crisis económicas. Existen unas causas intrínsecas de las que somos responsables, de una u otra forma, en uno u otro grado, todos quienes hemos colaborado a amasar esa mentalidad, a formular unas pautas o normas, o a utilizarlas o velar por su correcta aplicación. Es nuestra obligación reflexionar sobre esas causas y plantear los golpes de timón necesarios para enderezar el curso de la evolución del método y evitar que las desviaciones, los errores o los abusos alimenten las excusas para obviar su necesidad en la práctica de la disciplina.

Algunas de esas causas intrínsecas guardan relación con la práctica actual del siempre vindicado trabajo interdisciplinario, y la elección, ejecución y utilización posterior de los Ilamados estudios previos, dos bases fundamentales de la metodología. El análisis del estado de la cuestión de estos dos aspectos presidió el seminario "Ciencia y Patrimonio. Usos, abusos y necesidad", celebrado en Barcelona en los días en que se acabó este artículo, y que congregó a más de un centenar de profesionales de los diversos campos que intervienen en la restauración del patrimonio cultural en general, y del monumental en particular. La presentación que acompañaba la convocatoria (presidida por la frase de José Ortega y Gasset "Ciencia es todo aquello sobre lo cual siempre cabe discusión"), era suficientemente elocuente respecto de la situación que se vive actualmente y de las intenciones del debate propiciado, una vez más, por los organizadores del evento, Màrius Vendrell y Pilar Giraldez: "No siempre los estudios científicos, históricos o arqueológicos han sido de utilidad para restaurar, conservar o simplemente conocer el patrimonio. No obstante, existe cierta fascinación por la tecnología que produce un imaginario de exactitud y verdad absoluta que muchas veces nada o poco tiene que ver con la realidad, a menudo distorsionada por abusos de los resultados analíticos, un mal diseño experimental, la falta de rigor en la metodología (a veces inducida por una idea preconcebida de los resultados) o una errónea interpretación de los datos". Se trataba, según los promotores, de analizar cómo pueden la ciencia y la técnica "ayudar a conocer el patrimonio: hasta dónde se puede llegar, con qué limitaciones, con qué grado de certidumbre; y al mismo tiempo poner de manifiesto los abusos y malas interpretaciones que los datos supuestamente científicos han inducido, en ocasiones, a restauraciones equivocadas o perjudiciales".

Se trataba, en definitiva, de poner sobre la mesa de una manera cruda, descarnada, algunas de esas causas intrínsecas de la crisis del método; las que ciertamente, como he dicho, podemos intentar corregir "desde dentro". La primera impresión que se obtuvo tras escuchar a buena parte de los ponentes fue que en los últimos años los estudios científicos susceptibles de ser aplicados al patrimonio, en particular a los monumentos, han avanzado más, tanto en número como en sofisticación, que la confianza que se deposita en ellos; es decir, que la esperanza de quien ha de intervenir en esos monumentos en que realmente esos estudios sirvan para los objetivos que prevé el método: el conocimiento previo del objeto antes de reflexionar sobre los objetivos y el cómo debe actuarse en él, y de proyectar la solución más conveniente y eficaz.

El profesor e historiador del Arte Gerardo Boto, que trató del papel de los estudios de historia del arte, de la arquitectura y de la construcción en el conocimiento del monumento, denunció la sobreinformación distorsionadota que en ocasiones producen esos estudios indiscriminados, y, de manera especial, la retórica tecnológica (el "escaparatismo tecnológico") con que esos estudios se presentan, ya que seducen (a otros profesionales, y sobre todo, a gestores y políticos), mucho más de lo que aportan al conocimiento útil. Generan un ficción del conocimiento, dijo Boto, más que el conocimiento en si mismo, al tiempo que a menudo olvidan algo esencial como es el conocimiento del uso de los edificios en el pasado, tan importante o más que la evolución de su morfología (8).

En opinión del ingeniero Pere Roca, otorgar la bula de la infalibilidad a estudios por naturaleza aproximativos (como todos los que se basan en analizar un modelo, informático o no, que trata de sustituir la compleja realidad inabordable), compromete peligrosamente la eficacia de las conclusiones en que se basen los proyectos de actuación. Eso lo saben perfectamente, dijo Roca, los especialistas en esos estudios, pero a menudo lo obvian los proyectistas que actúan a continuación, sugestionados también por ese escaparatismo tecnológico que ha invadido las disciplinas del conocimiento.

En las densas jornadas de Barcelona, a parte de esas aportaciones que he comentado y algunas más, se sucedieron otras muchas, 
cuyo innegable interés particular se vio nublado por la ausencia de reflexiones que las interrelacionaran con los aportes de otros profesionales o la práctica de otras disciplinas. Se puso en evidencia, por lo tanto, lo que a mi juicio es la principal causa del relativo fracaso de la metodología renovada, o la causa de su retraso en alcanzar la plenitud de su eficacia. Me refiero a la inexistencia de una auténtica mentalidad interdisciplinaria entre los profesionales que intervienen en la restauración monumental. De hecho, en España, apenas existen equipos ciertamente interdisciplinarios y se han hecho crónicas las erróneas secuencias de la incorporación de los diferentes profesionales en el proceso de restauración.

En la mayor parte de ocasiones el arquitecto responsable del proyecto o de la dirección de las obras recibe el encargo correspondiente cuando los estudios previos han sido realizados, por lo que no ha podido participar en la decisión de qué estudios son realmente necesarios, ni ha podido seguir su desarrollo, por lo que las conclusiones, por lo general, le interesan poco, si es que llega a conocerlas. Por otra parte los profesionales de los estudios del conocimiento (histórico o material), una vez entregadas esas conclusiones no participan de la reflexión conjunta previa al proyecto ni del seguimiento posterior de la obra, momentos en que podrían comprobar la rectitud de sus conclusiones y, llegado el caso, reelaborar las hipótesis, etapa ineludible de un proceso que quiera Ilamarse científico. Por su parte, el constructor (a menudo tratado únicamente como contratista) no sólo no ha participado en los estudios previos de carácter material, como tampoco en la fase de proyecto, ya que ha sido escogido a posteriori, cuando el proyecto está cerrado; y, además, ha sido elegido, no por su experiencia o conocimientos, sino por su mejor oferta económica ("mejor", claro está, en el sentido de más barata, no de más ajustada a la realidad de los costes previsibles).

Al margen de estas consideraciones, no puedo olvidar otra causa que a mi juicio ha influido en ralentizar la consolidación de la mentalidad que subyace en el método del que estamos tratando. Me refiero a la ausencia de aportaciones que sobre estas materias se publican en las revistas Ilamadas científicas o, en su caso, la inutilidad de la mayor parte de las que tienen un carácter teórico o académico, especialmente las redactadas por profesores e investigadores universitarios. No sirve de excusa, pero sí como una de las posibles causas, el hecho de que las evaluaciones de dichas revistas, como las de los propios autores, se hagan por parte de angélicos agentes externos y que se basen, no en la eficacia práctica de esas posibles pero escasas aportaciones (prácticas, cuanto menos respecto del avance del discurso teórico), sino en parámetros tan ambiguos como el idioma en que se publican (al margen del idioma que utilicen los destinatarios mayoritarios de dichas aportaciones) y el número, no la calidad, de las citas que contienen; o las citas que provocan dichos artículos en artículos posteriores de otros profesores, a su vez exonerados de aportar utilidad práctica mediante sus escritos.

\section{CONCLUSIONES}

Un cuarto de siglo de investigación, desarrollo, formulación, difusión, puesta en práctica y análisis de los resultados de la nueva metodología de la restauración monumental ha de servirnos para poder plantear, por lo menos las bases, de unas conclusiones sobre la pervivencia de su validez actual y futura.

A mi juicio, la metodología que se fundamenta en la comprensión y valoración equitativa de las tres dimensiones esenciales del monumento: la documental, la arquitectónica y la significativa, y la consideración de la restauración monumental como una disciplina científica, técnica y creativa, basada en el conocimiento profundo del monumento y de su entorno, la objetivación de sus fines y la elección de los medios en función de su eficacia, siempre como fruto de un trabajo profesional interdisciplinario, sigue siendo totalmente válida, y posiblemente pueda serlo durante mucho tiempo (9).

Conviene, eso sí, seguir concibiendo el acto restaurador como un ejercicio, esencialmente, de conocimiento científico, de proyectación arquitectónica y, por último, de difusión y beneficio colectivo. Conviene también, naturalmente, precisar siempre cuál es, y en qué grado, el conocimiento del monumento que precisamos en cada caso; racionalizar por lo tanto las demandas de estudios (pero no en función del coste o de la oportunidad de realizarlos, sino de su real necesidad y de la presumible eficacia en el caso concreto). Conviene insistir en la necesidad de crear auténticos equipos interdisciplinarios para afrontar los complejos trabajos de restauración. Conviene que los arquitectos, a quienes corresponde en exclusiva la responsabilidad de proyectar, atiendan al conocimiento alcanzado, a los objetivos pactados y a los medios disponibles. Conviene adaptar siempre los medios a los fines (no utilizar los medios a nuestro alcance simplemente por esa facilidad, sino sólo los estrictamente necesarios y 
eficaces en cada actuación). Conviene seguir poniendo al alcance de la colectividad los efectos de la intervención y favorecer, cuando sea posible y compatible con su adecuada conservación, el uso colectivo de los monumentos. Conviene seguir exigiendo de la Administración pública la racionalización, en general, del contexto en que se produce la actividad (legislación, reglamentación, presupuestos, prioridades, etc.), y, en particular, la de los procesos que condicionan cada actuación concreta (el orden de los encargos, la correcta secuencia de incorporación de todos los profesionales en la actividad). Y, en definitiva, hacer del apego hacia el patrimonio monumental un escenario imprescindible para actuar en él, y del sentido común una herramienta polivalente en todas las etapas del proceso.

\section{BIBLIOGRAFÍA}

(1) Torsello.Paolo.Che cose il restauro?. Edit. Marsilio, Venezia 2006.

(2) Carbonara.Giovanni. La reintegrazione dell'imagine.Edit.Bulzoni, Roma 1976

(3) Rivera, Javier. Teoría e Historia de la Restauración. MMRP 1997

(4) Mora, Susana. La Restauración Arquitectónica en España 1850-1936.Antecedentes, criterios Kaher, Madrid 2002.

(5) Lacuesta, Raquel. Restauración arquitectónica en Cataluña en la segunda mitad del s.XIX.en Loggia ${ }^{\circ}$ 5. año II, 1997

(6) Jiménez, Alfonso Enmiendas parciales a la teoría del Restauro. I y II.En Logia $\mathrm{n}^{\circ}$ s 4 y 5 , año II, 1997

(7) Feiffer.Cesare. II progetto di conservazione. Edit.Franco Angeli, Milano 1989

(8) Rocchi Paolo y Piccirilli Carmen. Manuale della diagnostica. Edit.Kappa, Roma 2009

(9) Doglioni. Francesco. Nel restauro. Progetti per le architetture del passato.Edit. Marsilio. Venezia 2008

(10) Estebán, Juliá. Reflexiones en torno a la conservación de los bienes culturales en el siglo XXI En: Quaderns cientifics i Tecnics de Restauració Monumental. Diputació de Barcelona, Noviembre 2000 